\title{
Novel urinary biomarkers and their association with urinary heavy metals in chronic kidney disease of unknown aetiology in Sri Lank: a pilot study
}

\author{
K Wanigasuriya ${ }^{1}$, I Jayawardene ${ }^{2,3}$, C Amarasiriwardena ${ }^{2,3}$, R Wickremasinghe A $^{4}$
}

\begin{abstract}
Introduction Chronic kidney disease of unknown etiology (CKDu) has emerged as a significant public health problem in Sri Lanka. The role of environmental exposure to cadmium and arsenic in the aetiology of CKDu is still unclear. Identification of a panel of novel urinary biomarkers would be invaluable in the study of toxin mediated damage postulated to be the aetiology of CKDu.

Objectives The aims of this study were to evaluate the profile of novel urinary biomarkers in CKDu patients and identify any association with environmental exposure to heavy metals.

Methods Thirty seven randomly selected CKDu patients attending a renal clinic in the North Central Province and two control groups namely a farmer group $(n=39)$ and a non-farmer group $(n=40)$ from a non-endemic area were included in this comparative cross sectional study. Urine samples were analyzed for heavy metals and five urinary biomarkers.
\end{abstract}

Results CKDu patients had significantly elevated urinary levels of fibrinogen $(198.2 \mathrm{ng} / \mathrm{mg}$ creatinine $\mathrm{p}<0.001)$, clusterin $(3479 \mathrm{ng} / \mathrm{mg}$ creatinine $\mathrm{p}<0.001)$, cystatin-C (5124.8 $\mathrm{ng} / \mathrm{mg}$ creatinine $\mathrm{p}<0.001)$ and $\beta 2$-microglobulin $(9913.4 \mathrm{ng} / \mathrm{mg}$ creatinine $p<0.001)$ compared to the control groups. Fibrinogen and $\beta 2$-microglobulin were the best to discriminate CKDu patients from normal individuals with the receiver operator areas under the curve being 0.867 and 0.853 , respectively. Urinary fibrinogen and KIM-1 levels correlated positively with urinary arsenic levels. KIM-1 levels correlated positively with urinary mercury and lead levels but no correlation was seen with urinary cadmium levels.

Conclusions Fibrinogen and $\beta 2$-microglobulin have the potential of being a screening tool for detection of CKDu and may aid the early diagnosis of toxin mediated tubular injury in CKDu. Their usefulness need to be further validated in a larger epidemiological study of patients with early stages of CKDu.

Ceylon Medical Journal 2017; 62: 210-17

DOI: http://doi.org/10.4038/cmj.v62i4.8568

\section{Introduction}

Chronic kidney disease of unknown aetiology (CKDu), which emerged at the beginning of this century, has reached epidemic proportions in the North Central Dry Zone of Sri Lanka [1,2]. The disease burden is most prominent in the North Central Province and has extended to two adjacent provinces, namely, Uva and North Western provinces. The disease is not due to conventional risk factors such as diabetes, hypertension, chronic glomerulonephritis. The diagnosis of $\mathrm{CKDu}$ is based on exclusion of known aetiological factors of chronic kidney disease and presence of tubulo-interstitial pathology on renal biopsy $[3,4]$.

The population in the North Central Province is around 2.5 million according to the last census conducted in 2012 and farming is the main livelihood of the majority. $\mathrm{CKDu}$ mainly affects farming communities with poor socioeconomic background [5]. The estimated prevalence of $\mathrm{CKDu}$ in a community based study was reported as $16.9 \%$ in women and $12.9 \%$ in men, but the severe stages were seen more frequently in men, leading to a higher mortality and morbidity in men $[5,6]$.

Based on CKDu's clinical profile and risk factors, it was postulated that environmental toxins which affect vulnerable groups in a specific geographical area contribute to the onset and progression of the disease [7]. Several investigators have explored the aetiological contribution of exposure to various environmental toxins such as pesticides, microbial toxins and heavy metals [6,8-10]. The role of chronic exposure to cadmium (Cd) and arsenic (As) through environmental contamination of agrochemicals remains a highly debated topic among scientists [6,11-12]. The evidence regarding exposure to heavy metals as measured by levels of urinary excretion in patients and in controls and environmental samples is inconsistent [6,11-13].

1Faculty of Medical Sciences, University of Sri Jayewardenepura, Sri Lanka, 2Harvard School of Public Health, Boston, USA, 3Channing Laboratory, Department of Medicine, Brigham and Women's Hospital, Harvard Medical School, Boston, USA, 4Faculty of Medicine, University of Kelaniya, Sri Lanka

Correspondence: KW, e-mail: <kamaniw@usjp.ac.lk>. Received 28 March 2017 and revised version accepted 12 August 2017.

This is an open-access article distributed under the terms of the Creative Commons Attribution License, which permits unrestricted use, distribution, and reproduction in any medium, provided the original author and source are credited. 
There are limitations in using conventional screening tools such as serum creatinine and urinary albumin in the early diagnosis of renal damage. A new focus of interest are novel biomarkers in kidney injury. A number of promising tests have been developed which can be used for detection of early acute kidney injury in various clinical settings [1418]. The value of novel biomarkers in CKDu diagnosis has been evaluated recently [19-21]. Excretion patterns of some biomarkers may be useful in identifying nephrotoxicantinduced injury in the CKDu population. Kidney injury molecule-1 (KIM-1), a trans membrane glycoprotein and $\mathrm{N}$-acetyl-beta-D-glucosaminidase (NAG), another tubular dysfunction marker, are useful biomarkers of early stages of cadmium $(\mathrm{Cd})$ induced proximal tubule injury [22,23].

The aim of this pilot study was to identify the novel urinary biomarker profile in CKDu patients and to evaluate their association with urinary excretion of heavy metals. Fibrinogen, $\beta 2$-microglobulin, cystatin-C (Cys-C), clusterin and KIM-1 are the urinary biomarkers selected for this study.

\section{Methods}

A comparative cross sectional study was carried out on 37 patients with $\mathrm{CKDu}$ attending the renal clinic at Medawachchiya Hospital in the North Central Province and two control groups. Thirty seven consecutive patients who fulfilled the diagnostic criteria for suspected CKDu and had a serum creatinine level $\geq 2 \mathrm{mg} / \mathrm{dl}$ were recruited [3]. A farmer group $(n=39)$ from a non-CKDu endemic area from the Western Province was selected as a control group in order to achieve similar occupational exposure. To evaluate any environmental exposure specific to farmers, a non-farmer control group $(\mathrm{n}=40)$ was selected from among residents of the same area who volunteered. The residents were identified in consultation with the Grama Niladhari of the area. Inclusion criteria for both control groups were absence of urinary albumin, normal serum creatinine levels and absence of CKD risk factors. All subjects were residents and lived in the respective provinces for at least ten years. A control group from the endemic area was not considered because some subjects in whom conventional screening tests are negative, may have early tubular damage as a result of exposure to the same environmental nephrotoxins. These individuals may have elevated levels of urinary biomarkers.

Ethical approval for the study was obtained from Harvard Institutional Review Board (IRB)-Brigham and Women's Hospital, Office of Human Research Administration-Harvard School of Public Health, Boston, USA, and Ethical Review Committee, Faculty of Medical Sciences, University of Sri Jayewardenepura, Sri Lanka. Written informed consent was obtained from all participants.

An interviewer-administered questionnaire was used to collect information about demographic data, source of drinking water, cooking utensils and use of traditional medicines. Five $\mathrm{ml}$ of venous blood was drawn and serum creatinine was assayed in a reference laboratory in Sri Lanka. Spot urine samples were collected and $10 \mathrm{ml}$ was transferred into a trace metal grade $15 \mathrm{ml}$ falcon tube for metal and urinary biomarker analysis. Another $2 \mathrm{ml}$ of urine was transferred to a falcon tube containing $30 \mu \mathrm{l}$ of $2 \%$ sulfamic acid for mercury analysis. Urine samples were kept at -40 celsius at the time of collection and within five hours was transferred to a $-800 \mathrm{C}$ freezer until transportation to the laboratory in USA. The coded urine samples in dry ice were couriered by air to the Harvard School of Public Health Trace Metals Analysis Laboratory, Boston, USA.

Table 1. Demographic characteristics of CKDu patients and the two control groupst.

\begin{tabular}{llll}
\hline & $\begin{array}{l}\text { CKDu Patients } \\
(\mathbf{n = 3 7 )}\end{array}$ & $\begin{array}{l}\text { Farmer Controls } \\
(\mathbf{n}=\mathbf{3 9})\end{array}$ & $\begin{array}{l}\text { Non-farmer controls } \\
(\mathbf{n}=\mathbf{4 0})\end{array}$ \\
\hline Age (mean, SD) & $57.1(92)$ & $55.1(11.5)$ & $49.1(6.3)$ \\
\hline BMI (mean SD) & $21.0(3.1)$ & $20.2(3.9)$ & $23.0(3.7)$ \\
\hline Sex & & & $36(90)$ \\
Male (N,\%) & $27(73)$ & $36(92.3)$ & $4(10)$ \\
Female (N, \%) & $10(27)$ & $3(7.7)$ & $1.08(0.10)^{* *}$ \\
\hline Serum creatinine (mg/dl) & $3.0(1.18)$ & $1.0(0.04)^{* *}$ & $76.1(8.3)^{* *}$ \\
\hline eGFR (mean, SD) & $23.5(1.17)$ & $84.3(5.2)^{* *}$ & $0(0 \%)$ \\
\hline Family member with CKDu (\%) & $13(35.1)$ & $2(5.1)$ & $7.5 \%$ \\
\hline Use of traditional medicine & $27 \%$ & $25.6 \%$ & $17.5 \%$ \\
\hline Smoking & $37.8 \%$ & $30.8 \%$ & $45.0 \%$ \\
\hline Consumption of pond/ lake fish & $91.9 \%$ & $33.3 \%$ & \\
\hline$\dagger$
\end{tabular}

$\dagger$ Only variables in which there was a difference between groups are tabulated. $\# * * \mathrm{p}<0.001$ 
Table 2. Urinary biomarkers by group

\begin{tabular}{llllll}
\hline & & $\begin{array}{l}\text { CKDu Patients } \\
(\mathbf{n}=\mathbf{3 7})\end{array}$ & $\begin{array}{l}\text { Farmer Con- } \\
\text { trols }(\mathbf{n}=\mathbf{3 9})\end{array}$ & $\begin{array}{l}\text { Non-farmer } \\
\text { controls (n=40) }\end{array}$ & Significance \\
\hline $\begin{array}{l}\text { Fibrinogen ng/mg } \\
\text { creatinine }\end{array}$ & Mean (SD) & $198.2(478.8)$ & $2.97(5.48)$ & $6.87(4.93)$ & $\chi^{2}=56.866$ \\
\cline { 2 - 6 } & Median & 20.00 & 1.73 & 5.52 & $(\mathrm{p}<0.001)$ \\
& (IQ range) & $(8.98-134.33)$ & $(0.59-3.20)$ & $(3.84-8.32)$ & \\
\hline $\begin{array}{l}\boldsymbol{\beta}-\mathbf{2} \text { microglobulin } \\
\text { ng/mg creatinine }\end{array}$ & Mean (SD) & $9913.4(13578)$ & $159.5(225.1)$ & $174.7(233.4)$ & $\chi^{2}=37.812$ \\
& Median & 4643.544 & 55.26 & 117.58 & $(\mathrm{p}<0.001)$ \\
& (IQ range) & $(248.52-$ & $(22.51-234,69)$ & $(44.74-181.86)$ & \\
& & $15375.19)$ & & & \\
\hline $\begin{array}{l}\text { Clusterin ng/mg } \\
\text { creatinine }\end{array}$ & Mean (SD) & $3479(7864.9)$ & $582.6(666.2)$ & $1178(1095)$ & $\chi 2=7.943$ \\
& Median & 371.58 & 423.46 & 835.57 & $(\mathrm{p}<0.001)$ \\
& (IQ range) & $(221.86-1587.10)$ & $(283.21-606.73)$ & $(366.12-$ & \\
\hline $\begin{array}{l}\text { KIM-1 pg/mg } \\
\text { creatinine }\end{array}$ & Mean (SD) & $780.8(657.2)$ & $499.5(352.7)$ & $506.7(280.8)$ & $\chi 2=5.068$ \\
& Median & 505.10 & 412.04 & 402.67 & $(\mathrm{p}=0.079)$ \\
\hline $\begin{array}{l}\text { Cystatin-C ng/mg } \\
\text { creatinine }\end{array}$ & Mean (SD) & $5124.8(9468.3)$ & $105.8(138.8)$ & $305.8(346.7)$ & $\chi 2=19.457$ \\
& Median & 681.28 & 74.98 & 243.46 & $(\mathrm{p}<0.001)$ \\
& (IQ range) & $(42.75-3650.43)$ & $(56.54-103.35)$ & $(95.75-362.61)$ & \\
\hline
\end{tabular}

Table 3. Sensitivity and specificity of urinary biomarkers in identifying CKDu

\begin{tabular}{lllll}
\hline & $\begin{array}{l}\text { Area under the } \\
\text { curve (AUC) }\end{array}$ & Cutoff value & Sensitivity & Specificity \\
\cline { 2 - 5 } Fibrinogen & 0.867 & 2.58 & 0.90 & 0.395 \\
& & 7.45 & 0.80 & 0.816 \\
& 10.85 & 0.70 & 0.918 \\
\hline 及-2 microglobulin & 0.853 & 33.65 & 0.90 & 0.303 \\
& & 168.81 & 0.80 & 0.724 \\
& & 798.23 & 0.70 & 0.974 \\
\hline Cystatin C & 0.677 & 23.64 & 0.90 & 0.053 \\
& & 35.60 & 0.80 & 0.132 \\
& & 98.92 & 0.70 & 0.487 \\
\hline KIM-1 & 260.93 & 0.90 & 0.250 \\
& 0.619 & 336.46 & 0.80 & 0.368 \\
& & 418.71 & 0.70 & 0.526 \\
\hline Clusterin & 108.44 & 0.90 & 0.0 \\
& 0.457 & 180.60 & 0.80 & 0.092 \\
& & 271.52 & 0.70 & 0.224 \\
\hline
\end{tabular}


Table 4. Urinary heavy metal concentrations by group

\begin{tabular}{|c|c|c|c|c|c|}
\hline & & $\begin{array}{l}\text { CKDu Patients } \\
(n=37)\end{array}$ & $\begin{array}{l}\text { Farmer Con- } \\
\text { trols }(n=39)\end{array}$ & $\begin{array}{l}\text { Non-farmer } \\
\text { controls }(n=40)\end{array}$ & $\begin{array}{l}\text { Kruskal } \\
\text { Wallis test } \\
\text { Significance }\end{array}$ \\
\hline \multirow{3}{*}{$\begin{array}{l}\text { Lead }(\mu \mathrm{g} / \mathrm{g} \\
\text { creatinine })\end{array}$} & Mean (SD) & $1.20(0.27)$ & $3.05(1.26)$ & $0.76(0.64)$ & $\chi^{2}=63.147$ \\
\hline & Median & 0.99 & 2.91 & 0.58 & $(\mathrm{p}<0.001)$ \\
\hline & (IQ range) & $(0.66-1.63)$ & $(2.04-3.73)$ & $(0.41-0.84)$ & $\chi 2=62.849$ \\
\hline \multirow{3}{*}{$\begin{array}{l}\text { Manganese }(\mu \mathrm{g} / \mathrm{g} \\
\text { creatinine) }\end{array}$} & Mean (SD) & $4.65(2.96)$ & $4.31(2.78)$ & $0.90(0.51)$ & $(p<0.001)$ \\
\hline & Median & 3.67 & 4.06 & 0.77 & $\chi 2=28.903$ \\
\hline & (IQ range) & $(2.79-5.82)$ & $(2.38-5.95)$ & $(0.54-1.20)$ & $(\mathrm{p}<0.001)$ \\
\hline \multirow{3}{*}{$\begin{array}{l}\text { Cadmium }(\mu \mathrm{g} / \mathrm{g} \\
\text { creatinine) }\end{array}$} & Mean (SD) & $0.68(0.39)$ & $1.32(1.27)$ & $0.54(0.31)$ & \\
\hline & Median & 0.57 & 0.91 & 0.48 & $\chi 2=0.219$ \\
\hline & (IQ range) & $(0.44-0.81)$ & $(0.73-1.69)$ & $(0.32-0.68)$ & $(p=0.896)$ \\
\hline \multirow{3}{*}{$\begin{array}{l}\text { Arsenic }(\mu \mathrm{g} / \mathrm{g} \\
\text { creatinine) }\end{array}$} & Mean (SD) & $58.01(75.12)$ & $51.44(45.41)$ & $47.23(55.36)$ & \\
\hline & Median & 33.76 & 33.19 & $34 / 11$ & $\chi 2=25.061$ \\
\hline & (IQ range) & $(21.25-58.09)$ & $(22.32-56.24)$ & $(22.93-48.18)$ & $(p<0.001)$ \\
\hline \multirow{3}{*}{$\begin{array}{l}\text { Mercury }(\mu \mathrm{g} / \mathrm{g} \\
\text { creatinine })\end{array}$} & Mean (SD) & $1.45(1.40)$ & $1.76(1.15)$ & $0.91(0.73)$ & \\
\hline & Median & 1.44 & 1.46 & 0.66 & \\
\hline & (IQ range) & $(0.98-2.45)$ & $(0.76-2.39)$ & $(0.53-0.99)$ & \\
\hline
\end{tabular}

Urinary analyses for $\mathrm{Pb}, \mathrm{Cd}, \mathrm{As}$ and $\mathrm{Mn}$ concentrations were performed using external calibration with 5 standards at concentrations ranging from 0 to $10 \mathrm{ng}$ ml- 1 using inductively coupled plasma-mass spectrometer equipped with dynamic reaction cell. Mercury assay was performed using the Direct Mercury Analyzer 80 (DMA-80, Milestone Inc., CT). Urinary fibrinogen, clusterin, cystatin- $\mathrm{C}$ and $\beta 2-$ microglobulin were measured using a commercially available multiplexed luminex based kit from Millipore (Billerica, MA). KIM-1 was measured by using Magnetic bead-based multiplex assay for the Luminex ${ }^{\circledR}$.

\section{Statistical analysis}

Categorical variables were presented as percentages and continuous variables were tabulated as means with standard deviations, medians and ranges for comparison. Urinary biomarkers and metal concentrations are presented as normalized for urine creatinine. The distribution of the original urinary metal and urinary metal concentrations normalized for creatinine showed a right skewed pattern. SPSS version 20 software was used for data analysis. Kruskall-Wallis test was performed to compare the significance between the three groups. Receiver-operator characteristic (ROC) curves were plotted to determine the diagnostic accuracy of individual biomarkers. Spearman correlation coefficients between urinary biomarkers and urinary heavy metals were examined to look for correlations.

\section{Results}

Demographic characteristics of CKDu patients, farmer controls and non-farmer controls are shown in Table 1. Modified diet in renal disease (MDRD) equation was used to calculate eGFR. The majority of CKDu patients $(67.5 \%)$ were farmers and others were involved in part time farming activities. Thirteen $(35.1 \%)$ patients had at least one other family member diagnosed with CKDu. Use of traditional medicine, smoking, and consumption of lake or pond fish were higher among $\mathrm{CKDu}$ patients. More than two-thirds of the subjects in all three groups (range 67\% - 80\%) used aluminum utensils for cooking.

\section{Urinary biomarkers}

Twenty-three (62.1\%) CKDu patients had albuminuria; 11 of them had urinary albumin in the range of $30-300 \mathrm{mg} / \mathrm{g}$ creatinine and the other 12 had urinary albumin $>300$ $\mathrm{mg} / \mathrm{g}$ creatinine. Urinary fibrinogen, clusterin, Cys-C and $\beta 2$-microglobulin were significantly elevated in $\mathrm{CKDu}$ patients compared to the two control groups (Table 2). The comparison of receiver operator characteristics of biomarker levels revealed that fibrinogen and $\beta 2$ microglobulin performed the best in discriminating CKDu patients and both control groups taken together with the areas under the curve being 0.867 and 0.853 , respectively (Table 3 and Figure 1). For Cys-C, KIM-1 and clusterin, the areas under the curve were $0.677,0.619$ and 0.457 , respectively (Table 3 ). In order to determine suitable biomarker values that best differentiates CKDu from 
Table 5. Correlation between urinary biomarkers and urinary heavy metals

\begin{tabular}{llllll}
\hline & Lead & Manganese & Cadmium & Arsenic & Mercury \\
& & \multicolumn{2}{c}{ Spearman correlation coefficients } & & \\
\hline Fibrinogen & $-0.353(p<0.001)$ & $0.055(p=0.564)$ & $-0.106(p=0.264)$ & $0.208(p=0.027)$ & $0.120(p=0.206)$ \\
$\begin{array}{l}\boldsymbol{\beta}-2 \text { Microglob- } \\
\text { ulin }\end{array}$ & $-0.153(p=0.108)$ & $0.186(p=0.051)$ & $0.036(p=0.704)$ & $0.123(p=0.195)$ & $0.329(p=<0.001)$ \\
Clusterin & $-0.121(p=0.202)$ & $-0.103(p=0.280)$ & $0.060(p=0.527)$ & $0.176(p=0.063)$ & $0.062(p=0.572)$ \\
KIM-1 & $0.032(p=0.737)$ & $0.101(p=0.274)$ & $0.180(p=0.056)$ & $0.198(p=0.036)$ & $0.269(p=0.004)$ \\
Cystatin-C & $-0.274(p=0.003)$ & $-0.063(p=0.514)$ & $-0.096(p=0.313)$ & $0.175(p=0.053)$ & $-0.017(p=0.860)$ \\
\hline
\end{tabular}

healthy individuals, the cutoff values and the corresponding specificity for a given sensitivity was calculated using the ROC curve (Table 3 ). The best performing biomarkers were fibrinogen and $\beta 2$-microglobulin as indicated by the area under the curve. The specificity of Cys-C, KIM-1 and clusterin were generally below $50 \%$ when the sensitivity was in the range of $70 \%-90 \%$. At a sensitivity of $80 \%$, the specificity was $81.6 \%$ for fibrinogen and $72.4 \%$ for $\beta 2$-microglobulin. At a sensitivity of $90 \%$ the specificity was low for both these biomarkers.

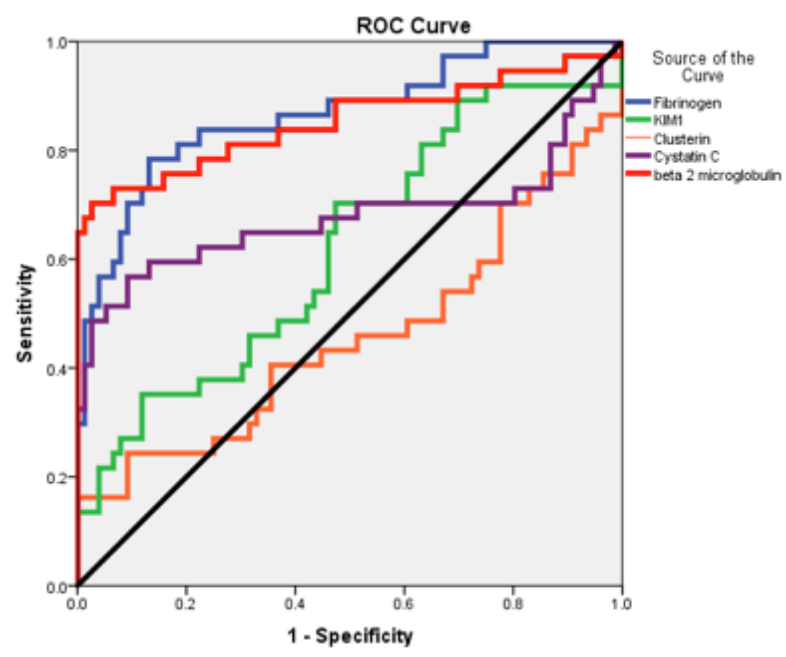

Figure 1. Receiver operator characteristics (ROC) curve of biomarkers

\section{Heavy Metals}

There were significant differences in urinary $\mathrm{Pb}$, $\mathrm{Mn}, \mathrm{Cd}$ and $\mathrm{Hg}$ levels between the three groups (Table 4). Urinary $\mathrm{Pb}$ levels were significantly higher in farmer controls from the non-endemic area compared $\mathrm{CKDu}$ patients and non-farmer controls. Urinary $\mathrm{Mn}$ and $\mathrm{Hg}$ levels in $\mathrm{CKDu}$ patients and in the farmer control group were significantly higher than in the non-farmer controls. Urinary $\mathrm{Cd}$ levels were significantly higher in farmer controls compared to $\mathrm{CKDu}$ patients and non-farmer controls. There was no significant difference in urinary As levels between the 3 groups.

The correlation between urinary biomarker levels and urinary metal concentrations are shown in Table 5. Urinary fibrinogen correlated positively with urinary As and urinary $\mathrm{Pb}$ levels. $\beta 2$-microglobulin correlated positively with urinary $\mathrm{Hg}$ levels and KIM-1 correlated with urinary As and urinary $\mathrm{Hg}$ levels. KIM-1 and beta 2 microglobulin were not correlated with urinary $\mathrm{Cd}$ levels.

\section{Discussion}

Urinary biomarkers are now considered potential markers for early detection of renal injury as well as a valuable research tool in evaluating environmental induced toxin damage. Urinary albumin and serum creatinine are the investigations currently available in Sri Lanka to screen for CKDu. This study indicates that urinary albumin is not a sensitive marker for early detection of CKDu as albuminuria was detected in only $62.1 \%$ of CKDu patients and only $32.4 \%$ had albumin-creatinine ratio (ACR) above $300 \mathrm{mg} / \mathrm{g}$ creatinine, the level which can be detected by the albustix method.

Urinary biomarkers of fibrinogen, clusterin, Cys-C and $\beta 2$-microglobulin were significantly elevated in $\mathrm{CKDu}$ patients compared to the two control groups. The KIM1 was of borderline significance $(\mathrm{p}=0.079)$. Fibrinogen and $\beta$-2-microglobulin were the most significant in discriminating known CKDu patients from the control group with normal kidney function.

Elevated urinary biomarkers in CKDu patients have been reported in previous studies. Urinary alpha1microglobulin are elevated in those with early stages of $\mathrm{CKDu}$ compared to unaffected controls whereas NAG is elevated only among patients with stage $5 \mathrm{CKDu}$ [19]. Another study reported that the mean urinary $\beta 2$ microglobulin was significantly higher among $\mathrm{CKDu}$ patients compared to controls [20]. De Silva et al. demonstrated that urinary KIM-1 and NGAL are capable of detecting early renal damage in the absence of albuminuria among farming communities in Southern Sri Lanka [21]. Our findings indicate that fibrinogen and $\beta 2$-microglobulin best distinguishe between diagnosed CKDu patients and persons with normal kidney function. 
Cys-C, KIM-1 and clusterin had very low specificities for given sensitivities even when comparing diagnosed CKDu patients in stage 3 or above with persons who had normal kidney function. Hence it is likely that these three biomarkers do not have the potential of being good screening tests. We observed a high false positive rate and this might be even higher in a sample with early stages of CKD. As this study was carried out in patients with established renal dysfunction, it is difficult to know the levels of these two biomarkers in patients with early CKDu. A study with a larger sample is necessary to explore this issue and in such a sample the cut off values may also be different.

This study was conducted as a pilot study and we did not have any data about the levels of these urinary markers. Therefore, we were unable to calculate a sample size a priori. Post hoc analysis shows that the study had a power of $83.9 \%$ to detect the smallest difference in fibrinogen levels of of $3.5 \mathrm{ng} / \mathrm{mg}$ creatinine.

Several authors have suggested that exposure to $\mathrm{Cd}$ and As through agrochemicals are likely risk factors of CKDu $[11,12,22]$. In the present study, we used urinary $\mathrm{Cd}$ as an indicator of chronic exposure to, and the total body burden of, cadmium. The farmer control group had significantly higher urinary Cd levels $(0.91 \mu \mathrm{g} / \mathrm{g}$ creatinine $)$ than the CKDu group $(0.572 \mu \mathrm{g} / \mathrm{g}$ creatinine $)$ and the nonfarmer controls $(0.48 \mu \mathrm{g} / \mathrm{g}$ creatinine $)$ indicating possible occupational exposure to $\mathrm{Cd}$ in the farmer population. Studies have shown that urinary $\mathrm{Cd}$ levels in unexposed populations are normally below $0.5 \mu \mathrm{g} / \mathrm{g}$ creatinine which is similar to that of the CKDu and non-farmer control groups in our study [23]. The critical urinary Cd concentration that is associated with the onset of renal injury has been found to be approximately 2 to $10 \mu \mathrm{g} / \mathrm{g}$ creatinine, which corresponds to a renal cortical $\mathrm{Cd}$ concentration of approximately 150 to $200 \mu \mathrm{g} / \mathrm{g}$ tissue [24]. In more recent studies conducted in the general population, urinary $\mathrm{Cd}$ levels below the accepted threshold of $2 \mu \mathrm{g} / \mathrm{g}$ creatinine have been shown to be associated with kidney disease and albuminuria [25]. Haddam et al. concluded that these associations could be due to influence of confounders such as diuresis, smoking or co-excretion with urinary proteins rather than direct effect of Cd [26]. The mean UCd concentration in CKDu patients and controls in our study is even below these threshold limits. However, the impaired renal function can have some effect on the excretion of $\mathrm{Cd}$ as shown in another study conducted on urine samples from patients in CKDu stages 1-4, and from their relatives and Japanese controls. This study showed a decline of mean UCd according to CKDu stage (Stage 1 showed $0.84 \mu \mathrm{g} / \mathrm{g}$ creatinine and stage 4 showed $0.44 \mu \mathrm{g} / \mathrm{g}$ creatinine) [19]. The mean UCd levels in cases ( 0.84 and $0.44 \mu \mathrm{g} / \mathrm{g}$ creatinine) and relative controls $(0.49 \mu \mathrm{g} / \mathrm{g}$ creatinine $)$ in the same study had remarkably lower cadmium excretion levels in urine compared with the Japanese controls $(1.79 \mu \mathrm{g} / \mathrm{g} \mathrm{Cr})$ indicating low levels of exposure in endemic areas [19].

UAs levels reflect recent exposure. In our study, there was no significant difference between the mean UAs concentrations between the three groups, but the levels were higher than the US population data indicating possible exposure. Both seafood and rice can contribute to elevated UAs levels [27-30]. In the present study, we did not gather information about the sea fish intake of the participants. Rice cultivators can accumulate both inorganic and organic forms of arsenic. The proportion of inorganic arsenic in rice grain differs according to the variety $[29,30]$. Urinary $\mathrm{Pb}$ levels were significantly higher in farmer controls than CKDu patients and non-farmer controls. Urinary Mn and $\mathrm{Hg}$ levels in both farmer groups were significantly higher than in the non-farmer controls. Factors such as sea fish consumption, which is a common source of $\mathrm{Hg}$, should be investigated in future studies.

There is interest in identifying sensitive biomarkers to monitor heavy metal exposure as early intervention can prevent long-term renal effects. We found positive correlations between fibrinogen and UPb and UAs; $\beta 2$ microglobulin with UHg and KIM-1 with UAs. There was no correlation between any of the biomarkers and UCd. Moriguchi et al. described increased urinary excretion of NAG, retinol binding protein (RBP), $\alpha 1-$ microglobulin and $\beta 2$ - microglobulin, as earliest effects of $\mathrm{Cd}$ induced renal damage [29]. However, our study did not find any correlation between KIM-1 and $\beta 2$-microglobulin and urinary Cd levels. In lead exposed workers, urinary excretion of KIM-1 was shown to correlate with blood lead levels better than other renal injury biomarkers, including NGAL, $\alpha 1$-microglobulin, and $\beta 2$-microglobulin [30]. Urinary biomarkers have not been used to evaluate arsenic induced nephrotoxicity.

\section{Limitations}

Patients who attend renal clinics in endemic regions are in advanced stages of $\mathrm{CKDu}$. The patients who were included in this study were in CKDu stage 3 and above. Urinary heavy metal excretion may have been affected to some degree due to the poor renal function. We propose to include patients with CKDu stages 1 and 2 in community screening in our next study.

\section{Conclusion}

Albuminuria is not a sensitive test for CKDu screening. Urinary excretion of fibrinogen and $\beta 2$-microglobulin should be considered as potential tools for screening for $\mathrm{CKDu}$ in Sri Lanka. Fibrinogen, $\beta 2$-microglobulin and KIM-1 would be valuable markers in identifying toxin mediated early tubular damage. These findings need to be validated in a larger study, which includes patients with early CKDu.

\section{Acknowledgements}

All urinary kidney injury biomarkers reported in the manuscript were measured in the laboratory of Dr. Vishal S. Vaidya at Brigham and Women's Hospital, Harvard Medical School, Boston MA. We thank Dr. Vaidya and his team for conducting these measurements and to Dr. Robert $\mathrm{O}$ Wright for his contribution in laboratory analysis. 


\section{Funding}

This study was partly supported by a research grant from the Ceylon College of Physicians.

\section{Conflicts of interest}

Authors declare that there are no conflicts of interest.

\section{References}

1. Hittarage A. Chronic renal disease in North Central Province of Sri Lanka. Anuradhapura Medical Journal 2004; 3-5.

2. Athuraliya TN, Abeysekera DT, Amerasinghe PH et al. Prevalence of chronic kidney disease in two tertiary care hospitals: high proportion of cases with uncertain etiology. Ceylon Med J 2009; 54: 23-25.

3. Circular of the Ministry of Health Care and Nutrition dated 24 December 2016.

4. Nanayakkara S, Komiya T, Ratnatunga $\mathrm{N}$ et al. Tubulo-interstitial damage as the major pathological lesion in endemic chronic kidney disease among farmers in North Central Province of Sri Lanka. Environ Health Prev Med 2012:17(3):213-2

5. Athuraliya NTC, Abeysekera TDJ, Amerasinghe PH, Kumarasiri R, Bandara P, Karunaratne U et al. Uncertain etiologies of proteinuric-chronic kidney disease in rural Sri Lanka. Kidney Int 2011; 80: 1212-1221.

6. Jayatilake N, Mendis S, Maheepala P, Mehta FR; On behalf of the CKDu National Research Project Team Chronic kidney disease of uncertain aetiology. Prevalence and causative factors in a developing country. BMC Nephrol 2013;14:180

7. Wanigasuriya KP, Peiris-John RJ, Wickremasinghe R, Hittarage A. Chronic renal failure in North Central Province of Sri Lanka: an environmentally induced disease. Trans R Society of Trop Med Hyg 2007;101:1013-1017

8. Wanigasuriya KP, Peiris H, Ileperuma N, Peiris-John RJ, Wickramasinghe R. Could ochratoxin A in food commodities be the cause of chronic kidney disease in Sri Lanka? Trans R Soc Trop Med Hyg 2008; 102: $726-728$

9. Desalegn B, Nanayakkara S, Harada KH et al. Mycotoxin detection in urine samples from patients with chronic kidney disease of uncertain aetiology in Sri Lanka. Bull Environ ContamToxicol. 2011;87(1):6-10.

10. Wanigasuriya KP, Peris-John R, Wickramasingha R, Chronic Kidney disease of unknown etiology in Sri Lanka; Is cadmium a likely cause? BMC Nephrology 2011;12:32

11. Bandara JMRS, Senevirathna DMAN, Dasanayake DMRSB et al. Chronic renal failure among farm families in cascade irrigation systems in Sri Lanka associated with elevated dietary cadmium levels in rice and freshwater fish (Tilapia). Environ Geochem Health 2008; 30:465-78.
12. Bandara JMRS, Wijewardena HVP, Liyanege J, Upul MA, Bandara JMUA. Chronic renal failure in Sri Lanka caused by elevated dietary cadmium: Trojan horse of the green revolution. Toxicology Letters 2010; 198(1):33-39.

13. Levine KE, Hoponick Redmon J, Elledge MF et al. Quest to identify geochemical risk factors associated with chronic kidney disease of unknown etiology $(\mathrm{CKDu})$ in an endemic region of Sri Lanka-a multimedia laboratory analysis of biological, food, and environmental samples. Environ Monit Assess 2016;188:548

14. Vaidya VS, Ferguson M.A, Bonventre JV. Biomarkers of Acute Kidney Injury. Annu Rev Pharmacol Toxicol 2008; 48:463-493.

15. Vaidya VS, Ozer JS, Dieterle F et al.Kidney injury molecule-1 outperforms traditional biomarkers of kidney injury in preclinical biomarker qualification studies. Nat Biotechno 12010; 28, 478-485.

16. Bonventre JV, VaidyaVS, Schmouder R. Feig P, Dieterle, F. Next-generation biomarkers for detecting kidney toxicity. Nat Biotechnol 2010;28: 436-440.

17. Mishra J, Dent C, TarabishiR et al. Neutrophil gelatinase-associated lipocalin (NGAL) as a biomarker for acute renal injury after cardiac surgery. Lancet 2005; 365: 1231-38

18. Mohamed, MF,Endre ZH, Buckley NA.Role of biomarkers of nephrotoxic acute kidney injury in deliberate poisoning and envenomation in less developed countries. Br J Clin Pharmacol 2015: 80:1. 3-19

19. Nanayakkara S, Senevirathna STMLD, Karunaratne $\mathrm{U}$ et al. Evidence of tubular damage in the very early stage of chronic kidney disease of uncertain etiology in the North Central Province of Sri Lanka: a crosssectional study. Environ Health Prev Med 2011 doi:10.1007/s12199-011-0224-Z

20. Siriwardhana EA, Perera PA, Sivakanesan R, Abeysekara T, Nugegoda DB, WeerakoonKG Is the staple diet eaten in Medawachchiya, Sri Lanka, a predisposing factor in the development of chronic kidney disease of unknown etiology? A comparison based on urinary beta2-microglobulin measurements. BMC Nephrol 2014; 15:103.

21. De Silva PMCS, Mohammed Abdul KS, Eakanayake EMDVet al. (2016) Urinary Biomarkers KIM-1 and NGAL for Detection of Chronic Kidney Disease of Uncertain Etiology (CKDu) among Agricultural Communities in Sri Lanka. PLoS Negl Trop Dis 2016;10(9):e0004979.

22. Jayasumana MACS, Paranagama PA, Amarasinghe MD et al. Possible link of chronic arsenic toxicity with chronic kidney disease of unknown etiology in Sri Lanka. Journal of Natural Sciences Research 2013;3(1):64-73.

23. Roels H, Bernard A, Buchet JP, Goret A, Lauwerys R, Chettle DR, Harvey TC, Haddad IA. Critical concentration of cadmium in renal cortex and urine. Lancet 1979;1:221 
24. Navas-Acien A, Tellez-Plaza M, Guallar E, Muntner P, Silbergeld E, Jaar B, Weaver V: Blood Cadmium and Lead and Chronic Kidney Disease in US Adults: A Joint Analysis. Am J Epidemiol 2009;170:1156-64.

25. Ferraro PM, Costanzi S, Naticchia A, Sturniolo A, Gambaro G. Low level exposure to cadmium increases the risk of chronic kidney disease: analysis of the NHANES 1999-2006 BMC Public Health $2010 ; 10: 304$

26. Haddam N, Samira S, Dumont X et al Confounders in the assessment of the renal effects associated with low level urinary cadmium: an analysis in industrial workers. Environmental Health: A Global Access Science Source 2011, 10, 37.

27. Caldwell KL, Jones RL, Verdon CP, Jarrett JM, Caudill SP, Osterloh JD. Levels of urinary total and speciated arsenic in the US population: National Health and Nutrition Examination Survey 2003-2004 Journal of Exposure Science and Environmental Epidemiology.2009; 19, 59-68

28. Molin, M, Ulven, SM, Dahl L et al. Urinary excretion of arsenicals following daily intake of various seafoods during a two weeks intervention. Food and Chemical Toxicology. 2014;,doi: http://dx.doi. org/10.1016/j.fet.2014.01.030

29. Moriguchi, J, InoueY, Kamiyama S et al. Cadmium and tubular dysfunction marker levels in urine of residents in non-polluted areas with natural abundance of cadmium in Japan. Int Arch Occup Environ Health 2010;83: 455-466.

30. Zhou R, Xu Y, Shen J et al. Urinary KIM-1: a novel biomarker for evaluation of occupational exposure to lead. Scientific Reports 6, 2016 doi:10.1038/ srep38930 